\title{
Striped domains of coarse-grained magnetite observed by X-ray photoemission electron microscopy as a source of the high remanence of granites in the Vredefort dome
}

Hiroto Kubo ${ }^{1}$, Norihiro Nakamura ${ }^{1 *}$, Masato Kotsugi ${ }^{2}$, Takuo Ohkochi ${ }^{3}$, Kentaro Terada ${ }^{4}$ and Kohei Fukuda ${ }^{5}$

\section{OPEN ACCESS}

Edited by:

Eric Font,

University of Lisbon, Portugal

Reviewed by:

Dario Bilardello,

University of Minnesota, USA

Melina Macouin,

Centre National de Recherche

Scientifique, France

*Correspondence:

Norihiro Nakamura,

Division of Geo-Environmental

Science, Graduate School of Science and Faculty of Science, Tohoku

University, 6-3 Aoba, Aramaki,

Aoba-ku, Sendai 980-8578, Japan norihironakamura21@gmail.com

Specialty section:

This article was submitted to Geomagnetism and Paleomagnetism,

a section of the journal

Frontiers in Earth Science

Received: 27 February 2015 Accepted: 02 June 2015

Published: 17 June 2015

Citation:

Kubo H, Nakamura N, Kotsugi M,

Ohkochi T, Terada K and Fukuda K (2015) Striped domains of coarse-grained magnetite observed

by $X$-ray photoemission electron microscopy as a source of the high remanence of granites in the Vredefort dome. Front. Earth Sci. 3:31. doi: 10.3389/feart.2015.00031
${ }^{1}$ Division of Geo-Environmental Science, Department of Earth Science, Graduate School of Science and Faculty of Science, Tohoku University, Sendai, Japan, ${ }^{2}$ Department of Materials Science and Technology, Tokyo University of Science, Tokyo, Japan, ${ }^{3}$ Hard-X-ray Spectroscopy Group, Division of the Research and Utilization, SPring-8/Japan Synchrotron Radiation Institute, Hyogo, Japan, ${ }^{4}$ Department of Earth and Space Science, Graduate School of Science, Osaka University, Toyonaka, Japan, ${ }^{5}$ Department of Earth and Planetary Science, The University of Tokyo, Tokyo, Japan

The characteristics of a coarse-grained high-remanence magnetite obtained from shocked Vredefort granite were investigated by X-ray magnetic circular dichroism (XMCD) analysis and X-ray absorption spectroscopy (XAS). The study utilized a spectroscopic photoelectron low-energy electron emission microscope (SPELEEM) and was conducted in the SPring-8 large-synchrotron radiation facility. It is generally believed that the strong and stable bulk remanence of Vredefort granites is due to the presence of minerals that have been strongly magnetized by either an impact-generated magnetic field or terrestrial lightning strikes. Although coarse-grained magnetite is traditionally characterized by weak coercivity and remanence, the specimen used in the present study exhibited high coercivity and an intense remanent magnetization. The presence of hematite lamellae observed on the partially oxidized magnetite specimen indicated an array of striped domains, intensifying a remanence and coercivity. We also conducted XAS and XMCD analyses on a natural lodestone permanent magnet produced by lightning strikes; while maghemite was found to be present, no magnetic domain structures were observed. Considering that the nucleation of hematite lamellae on magnetite/maghemite grains is due to oxidation, we attribute the intense remanent magnetization and magnetic hardening of Vredefort granites to post-impact hydrothermal activity.

Keywords: striped domain, corase-grained magnetite, XMCD, lodestone, post-impact hydorothermal activity, lightning, hematite lamellae

\section{Introduction}

The Vredefort dome is known as the largest and oldest $(2023 \pm 4 \mathrm{Ma})$ terrestrial impact structure. It is the deeply-exhumed remnant of the central uplift zone of a crater with an original diameter of $\sim 250 \mathrm{~km}$ (Reimold and Gibson, 1996; Gibson and Reimold, 2008) and exhibits strong aeromagnetic anomalies (Hart et al., 1995). Shocked Archean granitic rocks in the crystalline core 
of the Vredefort crater exhibit anomalously strong natural remanent magnetization (NRM), but with random centimeterscale orientation (Hart et al., 1995; Carporzen et al., 2005; Salminen et al., 2009). Previous researchers have hypothesized that the origin of these unique magnetic remanence properties is associated with very intense impact-generated small-wavelength magnetic fields that not only produce strong remanence, but also randomize the directions of the remanence (e.g., Hart et al., 1995; Cloete et al., 1999; Carporzen et al., 2005). This hypothesis has been rejected based on the observation of terrestrial lightning remagnetization in studies that utilized 10$\mathrm{m}$ borehole paleomagnetic measurements (Carporzen et al., 2012) and artificial lightning experiments (Salminen et al., 2013). Salminen et al. (2013) found that lightning-induced enhancement of remanence is due to the secondary production of partially oxidized magnetite, implying the presence of postimpact alteration. To understand these unusual remanence properties of Vredefort rocks, it might be necessary to consider the effect of impact-generated hydrothermal fluids that flow through fractures in the rocks (e.g., Osinski et al., 2013; Quesnel et al., 2013; Yokoyama et al., 2015). Such fluids enhance the remanence of primary low-coercivity coarse-grained magnetite by high-temperature oxidation.

Lightning-induced remanent magnetization (LIRM) is capable of remagnetizing grains with relatively low magnetic coercivities. Verrier and Rochette (2002) described alternatingfield (AF) demagnetization and clearly distinguished secondary variably-oriented LIRM from primary remanence in a high AF (Graham, 1961). Vredefort granitic rocks contain magnetite with two different grain sizes. The first size is often on the order of microns to millimeters and grains of this size are formed at about 3.0 Ga (e.g., Cloete et al., 1999; Nakamura et al., 2010). The second size is less than $1 \mu \mathrm{m}$ and grains of such size are formed within the interstices of the planar deformation features (PDFs) of quartz formed by impacts of 2.02 $\mathrm{Ga}$ (e.g., Cloete et al., 1999). Although it is generally believed that coarse-grained magnetites contain soft secondary components that are of "little geological interest" (Butler, 1992; Nakamura et al., 2010) showed that such magnetites embedded in biotite produce highly coercive and strong remanence, as determined by surface magnetic imaging using a scanning magneto-impedance magnetic microscope (Figure 1A). By Raman spectroscopy, they also found that a particular type of coarse-grained magnetite has lamellae of hematite. Salminen et al. (2013) succeeded in reproducing the unusual remanence properties by artificial lightning experiments, and showed that the source mineral was a coarse-grained partially oxidized magnetite with irregular magnetic microstructures and reduced grain size. They, however, undertook no further petrographic examination. Banfield et al. (1994) also proposed a relationship between the inter-grown nanometer-scale microstructure of massive-maghemite and the strong magnetic properties of the natural permanent magnet known as lodestone. It is well known that the magnetite-ilmenite intergrowths formed by the high-temperature oxidation of titanomagnetite, and not the multiple mineralogies, are what contribute to the highly stable remanence of a subdivision of minerals that include magnetite, maghemite, and non-magnetic ilmenite (e.g., Davis and Evans, 1976; Tucker and O'Reilly, 1980). Harrison et al. (2002) showed that magnetic susceptibility and remanence can be substantially enhanced by the formation of small amounts of magnetite and/or maghemite. However, there has been no report on the magnetic domain structure of highly magnetized natural rocks.

Almost all the Vredefort granitoid rocks with random and strong remanence that were examined by Carporzen et al. (2005) and Salminen et al. (2013) exhibited high-temperature metamorphism at $>800^{\circ} \mathrm{C}$ during post-impact event (e.g., Gibson and Reimold, 2008). This mechanism is capable of nearly or completely remagnetizing any remanence by subsequent cooling and/or post-impact hydrothermal activity (Salminen et al., 2009). We therefore investigated the effect of postimpact high-temperature metamorphism on the microtexture of magnetic minerals that have been strained or modified by a shock event or post-shock process. The investigation, which was undertaken at the SPring- 8 facility, utilized X-ray magnetic circular dichroism (XMCD) and X-ray absorption spectroscopy (XAS) using a spectroscopic photoelectron lowenergy electron emission microscope (SPELEEM). We also determined the crystallographic orientation of the minerals by electron backscatter diffraction (EBSD). This study was undertaken to address the question of why coarse-grained types of magnetite found in Vredefort rocks possess strong and high coercive remanence.

\section{Materials and Method}

\section{Sample Description}

The utilized shocked granite of $2.5 \mathrm{~cm}$ in diameter was drilled from an exposed crystalline basement of the Vredefort crater near Parys, South Africa, at $26^{\circ} 52.615^{\prime} \mathrm{S} 27^{\circ} 25.277^{\prime} \mathrm{E}$. The sample was provided by J. Salminen (University of Helsinki). The magnetic properties of the rock specimen had already been measured by J. Salminen, and comprised a density of $2599 \mathrm{~kg} / \mathrm{m}^{3}$, bulk NRM intensity of $9.1 \mathrm{~A} / \mathrm{m}$, Königsberger ratio (defined as the ratio of the NRM to the product of the magnetic susceptibility and geomagnetic field) of 75 , and Curie temperature of $588^{\circ} \mathrm{C}$ (which is equal to that of magnetite). Nakamura et al. (2010) examined the Raman spectroscopy of tip samples of thickness 1.0 and $1.5 \mathrm{~mm}$ and found the NRM intensities to be $13.1 \mathrm{~A} / \mathrm{m}$. They confirmed the presence of hematite lamellae on the host magnetite, which was embedded in chloritized biotite.

A thin section was made from the same tip sample examined by Nakamura et al. (2010) to examine the magnetic properties of the same grain by SPELEEM. Before the present experiments, the surface of the thin section was carefully polished using 1$\mu \mathrm{m}$-diameter diamond paste. The specimen was then finished by buff polishing using colloidal silica slurry. The thin section was subjected to an impulse field of several hundred milliTeslas in an out-of-plane orientation. We then rescanned the surface magnetic stray field on the thin section and detected the presence of highly coercive coarse-grained magnetites after 50-mT stepwise AF demagnetization using a scanning magnetoimpedance (MI) magnetic microscopy (Figure 1A). The grain was also examined by reflected light microscopy (Figure 1B) 


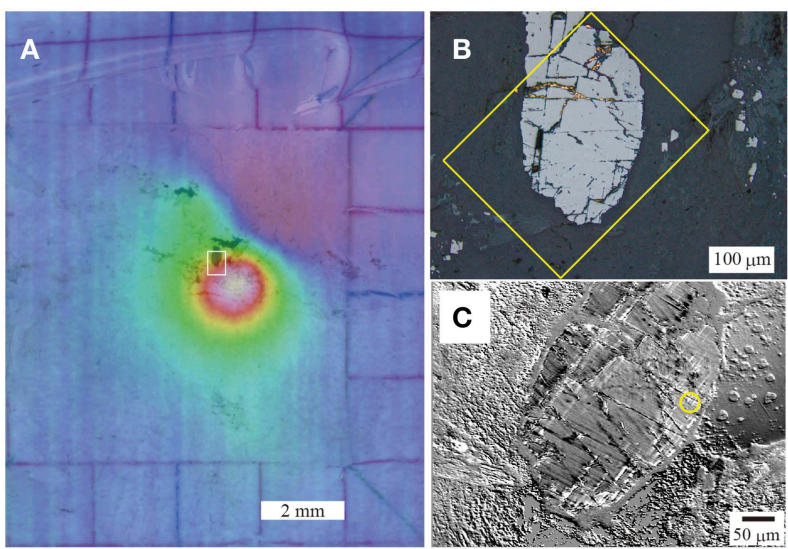

FIGURE 1 | Isothermally magnetized thin section of target magnetite obtained from Vredefort granite. (A) Microphotograph of superimposition of the thin section on a surface stray magnetic field obtained by a scanning $\mathrm{Ml}$ magnetic microscope. Note that there are two coarse-grained magnetites beneath the magnetic anomaly. The warm color indicates a strong stray magnetic field, white the white rectangle indicates the region of the image enlarged in (B). (B) Reflected-light optical image of the thin section. The surface was polished by $1 / 4-\mu \mathrm{m}$ diamond paste and finished by colloidal silica. The yellow rectangle indicates the area enlarged in (C). (C) Magneto-optical Kerr-effect microscope image of target magnetite. Note the three different arrays of lamellae (white and black). The yellow circle indicates the target area analyzed by a SPELEEM.

and magnetic Kerr-effect microscopy (Figure 1C), and this revealed three different orientations of lamellae. No fine-grained magnetites were found in the PDFs of the shocked quartz grain of the thin section, and this suggested that our coarsegrained magnetite was a major paleomagnetic carrier. This type of magnetite is unique and can be used to investigate the unusual magnetic properties of Vredefort granite. This enhances the reliability of using only one sample for this study.

\section{Spectroscopic Photoemission and low-energy electron microscope (SPELEEM)}

The experiments were performed using a SPELEEM produced by ElmitecCreative Commons Attribution License (CC BY)and a soft X-ray beamline (BL17SU) at the SPring-8 facility. The SPELEEM achieved a high spatial resolving power by the use of magnetostatic lenses, with a spatial resolution of $22 \mathrm{~nm}$. Three different excitation sources (highly brilliant circularly polarized soft X-ray, electron beam, and mercury lamp) were used to visualize the surface structure of the specimen. Circular-polarized soft X-rays were used to determine the spatially resolved chemical composition, the electronic states, and the magnetic domain structures of the specimen. The fine structure of the X-ray absorption spectrum (XAS) was used to analyze the mineral species and their spatial distribution. The XMCD effect was used to visualize the magnetic domain structures of the sample, and an electron beam was used to image the surface topological structure. The SPELEEM was used to simultaneously obtain information about the mineral species and their distribution as well as the magnetic domain structure and surface structure (Kotsugi et al., 2010, 2011).
We analyzed the X-ray absorption spectrum at the Fe $L_{3}$ absorption (706-712 eV) edge to determine the species of iron oxides, and used XMCD to visualize the magnetic domains. The XMCD-PEEM contrast was expressed as the intensity difference $I_{\mu}(+)-I_{\mu}(-)$, where $I_{\mu(+)}$ and $I_{\mu(-)}$ are respectively the image intensities determined by right-handed $(\mu(+))$ and lefthanded $(\mu(-))$ circularly-polarized lights. This image treatment contrasts due to non-magnetic factors, namely, the topography and chemical composition. Because $3 \mathrm{~d}$ transition metals ( $\mathrm{Fe}, \mathrm{Co}$, and $\mathrm{Ni}$ ) have $L_{3,2}$ absorption-edges that experience $2 \mathrm{p} \rightarrow 3 \mathrm{~d}$ core electron transitions at 700-730 eV, magnetic information about the $3 \mathrm{~d}$ electrons can be selectively obtained from the soft X-ray region. The Fe $L_{3,2}$-edge XMCD spectra of iron oxides such as magnetite exhibit three characteristic peaks with respect to the chemical environment (Pearce et al., 2006), namely, the $\mathrm{Fe}^{2+}$ octahedral peak (negative peak, $\sim 710.5 \mathrm{eV}$ ), $\mathrm{Fe}^{3+}$ tetrahedral peak (positive peak, $\sim 711.5 \mathrm{eV}$ ), and $\mathrm{Fe}^{3+}$ octahedral peak (negative peak, $\sim 712.5 \mathrm{eV}$ ).

Furthermore, to determine the differences between the crystallographic orientations of magnetite and those of hematite crystals, we employed EBSD using a scanning electron microscope (HITACHI S-3400N) equipped with HKL Flamenco for EBSD data acquisition.

\section{Results}

The SPELEEM was used to examine the remanence-carrying coarse-grained magnetite with lamellae, indicated by the yellow circle in Figure 1C. The chemical distribution of Fe on the Fe $L_{3}$ absorption edge was determined, and the local XAS spectra were extracted from areas 1-7 indicated by the colored lines in the XAS-PEEM image in Figure $2 \mathbf{A}\left(I_{\mu}(+)-I_{\mu}(-)\right)$. The green square (area 1 ), yellow square (area 2 ), and sky blue square (area 3) indicate regions within the host minerals; and the red triangle (area 4), blue square (area 5), violet triangle (area 6), and purple square (area 7) indicate portions of the lamellae. The corresponding X-ray absorption spectra of the host minerals are shown in Figure 2C, and those of the lamellae are shown in Figure 2D. Figure 2B shows the reference spectra of the Fe $L_{3,2}$ absorption edge of the iron oxides obtained from previous works (e.g., Kuiper et al., 1993; Pearce et al., 2006; Signorini et al., 2006; Kuzmin and Chaboy, 2014; Piquer et al., 2014). By comparing the spectral shapes of the data obtained from the present study with the references, the materials in areas 1-3 were determined to be magnetite, and those in areas 4-7 were determined to be hematite. The noticeable energy shift of $\sim 2 \mathrm{eV}$ observed between the present and reference data is due to the differing oxidation states, and such is not uncommon in magnetite (Waychunas et al., 1983; Okudera et al., 2012).

Figure 3A shows a clear image of the structure of the striped magnetic domain. The striped domains in the target magnetite have a horizontally sinuous pattern that is cut by the hematite lamellae that run perpendicular to the domain walls. The magnetic contrast of the magnetic domain structure is proportional to the cosine of the angle between the atomic magnetic moment and the incident light. Hence, the absence of a change in the contrast of the XMCD image indicates 


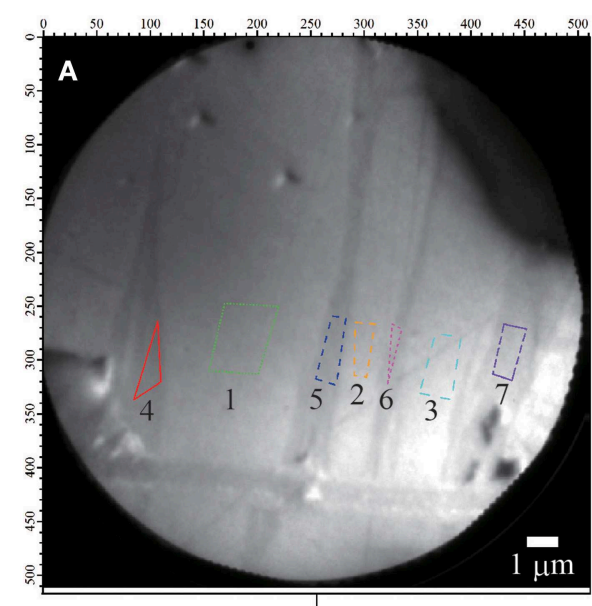

C

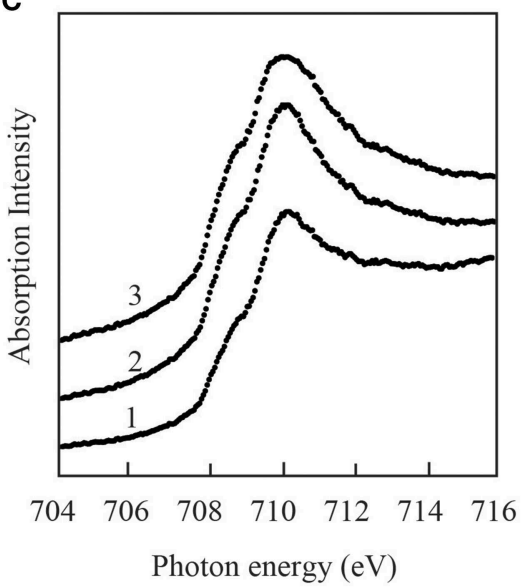

FIGURE 2 | X-ray $\mathrm{Fe} L_{3}$ edge chemical analysis of the magnetite specimen. (A) X-ray absorption spectroscopy (XAS) image of areas 1-7. (B) XAS spectra of the reference bulk samples of hematite $\left(\alpha-\mathrm{Fe}_{2} \mathrm{O}_{3}\right)$, maghemite $\left(\gamma-\mathrm{Fe}_{2} \mathrm{O}_{3}\right)$, and magnetite $\left(\mathrm{Fe}_{3} \mathrm{O}_{4}\right)$. (C) XAS spectra of areas
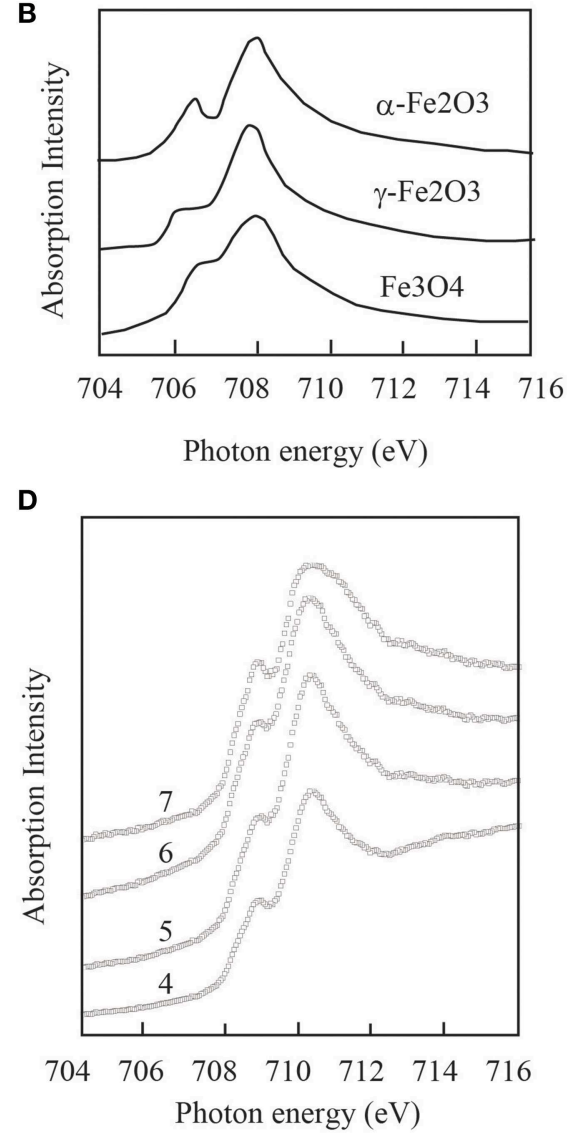

1-3 on the host mineral, indicating the presence of magnetite by comparison with the reference spectra. (D) XAS spectra of areas 4-7 on the lamellae, indicating the presence of hematite by comparison with the reference spectra. out-of-plane magnetization, while the observation of a change indicates in-plane magnetization. To further verify the outof-plane orientation of the magnetization, the specimen was rotated by $70^{\circ}$ about the vertical axis, while the same incident angle of the synchrotron radiation was maintained. As can be observed from Figure 3B, the brightness and contrast of the underlying striped magnetic domains revealed no change in the incident light of the synchrotron radiation, thereby indicating out-of-plane magnetization. The grayscale of the figure indicates the XMCD intensity. The dark portions of the image indicate upward-magnetization, and the white portions indicate downward-magnetization perpendicular to the surface. Owing to the difficulty of achieving saturated out-of-plane magnetization, it can be concluded that our magnetite possessed highly coercive and strong remanence.

Figure 3C shows the XAS and XMCD spectra of the magnetite region (white box) in Figure 3A. The XAS spectra of this region agree well with the reference spectra of the natural magnetite in Figure 2C. The XMCD was calculated as the difference between two different helicities (Figure 3C). The XMCD difference spectrum (Figure 3C, bottom) shows the well-defined peaks on the $L_{3}$ and $L_{2}$ edges, as characteristic of magnetite (Goering et al., 2006). The two negative peaks on the $L_{3}$ edge are mainly due to the octahedral $\mathrm{Fe}^{2+}$ and $\mathrm{Fe}^{3+}$ ions. The small positive peak in the middle is due to the tetrahedral $\mathrm{Fe}^{3+}$ ions. The opposite signs of the XMCD peaks produced by the Fe cations at the octahedral and tetrahedral sites indicate antiferromagnetic coupling. The magnetite crystals are thus ferrimagnetic. The cause of the little differences between the positive tetrahedral $\mathrm{Fe}^{3+}$ and negative octahedral $\mathrm{Fe}^{2+}$ is unknown. According to Piquer et al. (2014), the shift of the energies of the absorption peaks in the magnetite $\mathrm{XAS}$ spectra is due to a single-phase non-stoichiometric $\mathrm{Fe}_{3-\delta} \mathrm{O}_{4}$ oxide, and this modifies the structural arrangements at the $\mathrm{Fe}$ sites.

To compare the magnetic properties of the strongly magnetic Vredefort rocks with those of a lightning-created material (i.e., lodestone), we undertook the first ever XAS and XMCD analyses of natural lodestone (Figure 4), which has different 

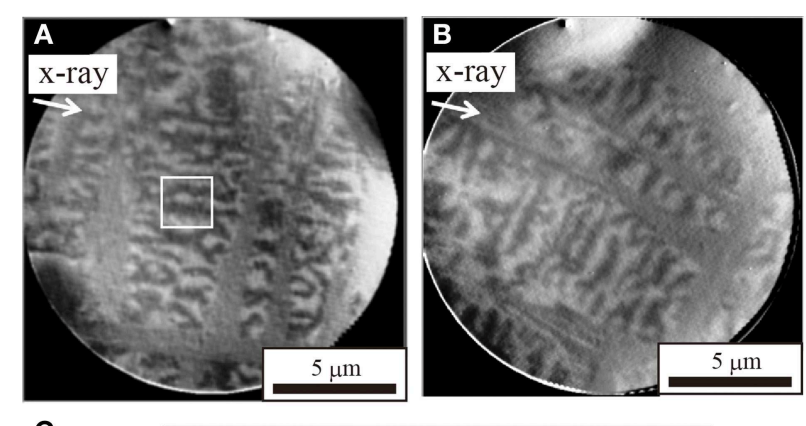

C

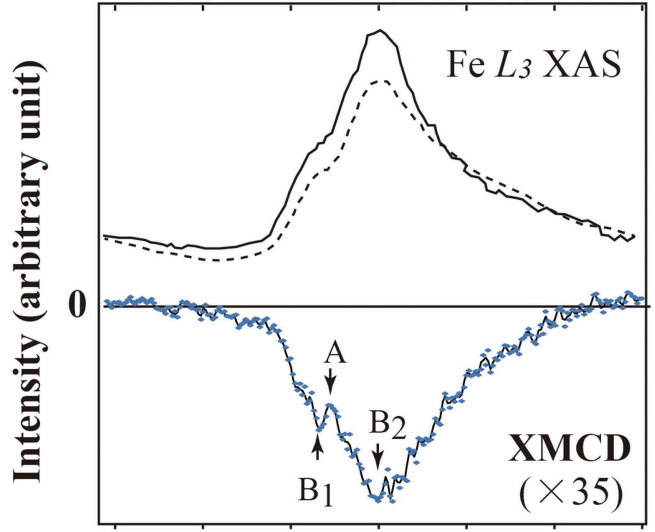

$\begin{array}{lllllll}704 & 706 & 708 & 710 & 712 & 714 & 716\end{array}$

Photon Energy (eV)

FIGURE 3 | Magnetic domain structure of the same area of the magnetite specimen in Figure 2. (A) XMCD images obtained using the difference between two different helicities acquired from the Fe $L_{3}$ absorption edge $(708.4 \mathrm{eV})$. The host magnetite is cut by a biaxial array of hematite lamellae, and has striped magnetic domains measuring less than about $4 \times 0.8 \mu \mathrm{m}$. The white box indicates the acquisition area for XAS and XMCD.

(B) Rotation of the image in (A) by $70^{\circ}$ about an axis vertical to the specimen. No change was observed in the domain structure, suggesting that the magnetic moment was directed toward the out-of-plane component. (C) XAS and XMCD spectra of the X-ray Fe $L_{3}$ edge of the magnetite matrix. The solid and dashed lines are the XAS spectra of two different helicities, and the blue dots indicate the XMCD spectrum, which shows a positive peak $(A)$ and two negative peaks $\left(B_{1}\right.$ and $\left.B_{2}\right)$

host mineralogy. Lodestone is a natural permanent magnet that attracts a paper clip (see Figure 4A), and the specimen used in this study was obtained from a magnetite ore, namely, a granitic pegmatites (Utah, USA, exact locality unknown). Figures 4B,C show a typical LEEM chemical component image and XMCD magnetic domain image of lodestone. Maghemite contained in a magnetite matrix cut by hematite lamellae was observed in the lodestone specimen (Figure 4B). The magnetite had a typical maze-like domain pattern (Figure 4C, bottom) and a characteristic disordered domain pattern (Figure 4C, upper). The XAS spectra of the $L_{3}$ and $L_{2}$ edges revealed the presence of maghemite (Figures 4D,E) (Brice-Profeta et al., 2005), and the XMCD spectra had two negative peaks (octahedral $\mathrm{Fe}^{2+}$ and $\mathrm{Fe}^{3+}$ ) and one positive peak (tetrahedral $\mathrm{Fe}^{3+}$ ). The XAS spectra of our Vredefort specimen were identical with those of the magnetite. However, the negative octahedral $\mathrm{Fe}^{2+}$ peak in the XMCD spectra was lower than that of lodestone, and the corresponding magnetic contribution was comparable to that of the octahedral $\mathrm{Fe}^{3+}$. The lower octahedral $\mathrm{Fe}^{2+}$ peak indicates partial oxidation of magnetite, and this suggests the presence of trace maghemite in the $L_{3}$ spectrum of the host magnetite, as also observed by Salminen et al. (2013). The magnetic domain structure of our partially oxidized magnetites contained a striped domain cut by hematite lamellae. The domain structure differs from the maze-like domains of the host magnetites in lodestone.

The crystal orientations of the minerals (i.e., magnetite and hematite) were obtained by EBSD in the same region of the XMCD analysis. The observed Kikuchi patterns of the magnetite grain clearly indicated an inverse spinel pattern (Figures 5A,B), while the hematite lamellae were observed to have trigonal patterns (Figures 5C,D). Figure 5E is an equal-area diagram of the lower hemisphere, and it shows that the $<0001>$ direction on the $c$-axis of the hematite is perpendicular to the $\{111\}$ plane of the magnetite. Although magnetization can be easily achieved in the $<111>$ direction of magnetite, the results of the XMCD analysis showed that the actual magnetization direction in the specimen was close to the hard $<100>$ axis.

\section{Discussion}

By 10-m borehole paleomagnetic measurements, Carporzen et al. (2012) showed that terrestrial lightning strike was the cause of the unusual magnetic rock properties of Vredefort granites. They also found that the natural remanence directions and their $0.55-\mathrm{m}$ magnetic anomaly vectors mostly lie along a great vertical circle and are consistent with the circular field expected for a current flowing horizontally in the northeastern direction. In addition, in the southeastern part of their study area, they observed a negative magnetic anomaly that extended concentrically around the center of the dome. This concentric magnetic anomaly has often been observed within an inner annular zone (e.g., Quesnel et al., 2013; Yokoyama et al., 2015), and it cannot be explained by only terrestrial lightning strike. Moreover, the inner annular zone might be a path for percolated post-hydrothermal fluids that flowed along fractures. Salminen et al. (2013) confirmed that the strong remanence of Vredefort granites was due to lightning strikes on the rocks, which previously contained partially oxidized magnetite within their microstructures. Our results also showed that coarse-grained magnetite in Vredefort granites contained an array of hematite lamellae, resulting from a partial oxidation. The presence of hematite lamellae might be prerequisite for the origin of high magnetization. It is therefore considered that preexisting partially oxidized magnetite in Vredefort granites intensify the remanence.

Our XMCD and XAS analyses showed that the hematite lamellae cut magnetic domains in the host magnetite. The opposite sense of the XMCD peaks produced by the Fe cations at the octahedral and tetrahedral sites indicated antiferromagnetic coupling of the cations (Monti et al., 2012). The grains of the host magnetite were divided into smaller grains measuring less than $5 \times 10 \mu \mathrm{m}$. These smaller parallel-piped grains correspond to a pseudo-single domain of magnetite in terms of size 


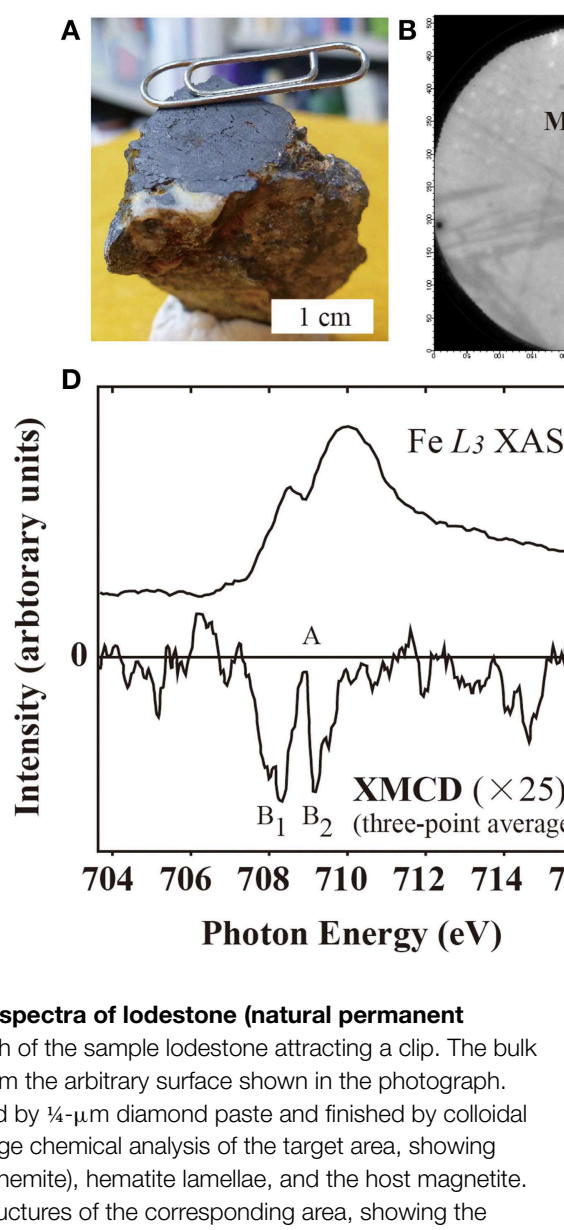

FIGURE 4 | Reference spectra of lodestone (natural permanent magnet). (A) Photograph of the sample lodestone attracting a clip. The bulk sample was obtained from the arbitrary surface shown in the photograph. The surface was polished by $1 / 4-\mu \mathrm{m}$ diamond paste and finished by colloidal silica. (B) $X$-ray Fe $L_{3}$ edge chemical analysis of the target area, showing oxidized magnetite (maghemite), hematite lamellae, and the host magnetite. (C) Magnetic domain structures of the corresponding area, showing the typical maze-like domain pattern of the magnetite cut by the hematite; no magnetic domain structure of the maghemite is discernible from the magnified image. (D) XAS and XMCD spectra of the X-ray Fe $L_{3}$ edge of the maghemite. The solid lines are the XAS and XMCD spectra, with the latter showing a positive peak $(A)$ and two negative peaks $\left(B_{1}\right.$ and $\left.B_{2}\right)$. (E) Comparison of the reference XAS spectrum of the $X$-ray $F e L_{3,2}$ and $K$ edge of maghemite with that of our sample. and shape (Butler and Banerjee, 1975). EBSD showed that the $\{0001\}$ planes of hematite contact the plane parallel to the $\{111\}$ planes of magnetite (the easily magnetized axes of magnetite and hematite are in the $<111>$ direction and $\{0001\}$ plane). The subdivision of the host magnetite by a biaxial array of hematite yielded new and smaller striped domains with out-of-plane magnetizations. Kasama et al. (2006) reported that the out-of-plane magnetization of magnetite thin films are directly associated with the presence of structural defects and antiferromagnetic coupling. Incidentally, based on an annealing experiment performed on a magnetite thin film for $4 \mathrm{~min}$ in air at $250^{\circ} \mathrm{C}$, Wei et al. (2006) showed that the appearance of striped domain structures was possibly caused by defect-related out-of-plane magnetization. Therefore, antiferromagnetically coupled hematite lamellae may immobilize the movement of striped domain walls. This suggests that the highly coercive and intense remanence of our coarse-grained magnetite is due to the presence of newly formed striped domains.

Yokoyama et al. (2015) reported the impact-induced hydrothermal alteration of the magnetic mineralogy of basalts obtained from an internal annular zone in the Vargeão impact structure in southern Brazil. This confirmed the formation of new secondary magnetic carriers such as magnetite and hematite along a highly hydrated and oxidized fracture. They proposed that the interaction of a hydrothermal fluid with brecciated basalts at higher than $200^{\circ} \mathrm{C}$ account for the occurrence of magnetite and hematite under no equilibrium with the atmosphere in an internal annular zone. This suggests that the observed concentric aeromagnetic anomalies were due to localized hydrothermal alteration along concentric faults, which acted as conduits for fluid circulation through the impact structure. Such a concentric and negative aeromagnetic anomaly has been observed in the Vredefort dome (Muundjua et al., 2007). The magnetite sample used in this study was taken from the region in which the anomaly was found, and this implies the occurrence of hydrothermal alteration in the impact structure.

Magnetite generally transforms to hematite by oxidation at high temperatures. Below $300^{\circ} \mathrm{C}$, magnetite oxidizes to the metastable phase known as maghemite $\left(\gamma-\mathrm{Fe}_{2} \mathrm{O}_{3}\right)$ by the migration of Fe cations (e.g., Gallagher et al., 1968). At higher temperatures (roughly above $600^{\circ} \mathrm{C}$ ), the oxidation of magnetite always results in the formation of secondary hematite (Colombo et al., 1965). The granite used in this study must have experienced a reheating event due to the impact of a 

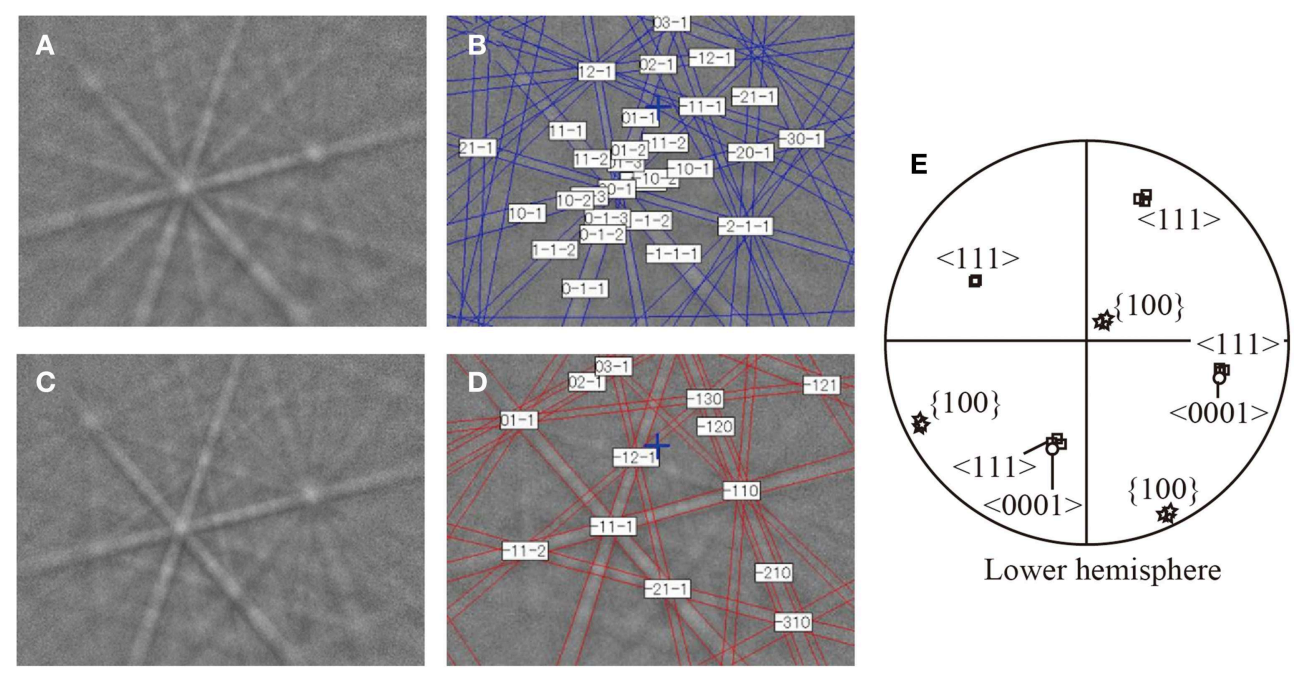

FIGURE 5 | EBSD Kikuchi patterns of (A,B) magnetite and (C,D) hematite. (E) Superposition of the crystal orientations of magnetite and hematite in the lower hemisphere. The $<0001>$ directions of hematite indicated by the open circles correspond to the $<111>$ directions of magnetite indicated by the open squares. The star symbols represent the $\{100\}$ plane of magnetite. meteorite. Based on the model of Ivanov (2005), the central part of the impact structure (of radius $\leq 15 \mathrm{~km}$ ) would have been extensively heated above $700^{\circ} \mathrm{C}$. Magnetites in the granite might have transformed into hematite by high-temperature oxidation induced by the impact of the meteorite $(2.03 \mathrm{Ga})$. By in situ X-ray spectroscopy, McCarty et al. (2014) found a biaxial array of hematite lamellae in oxidized magnetite after heating to $600^{\circ} \mathrm{C}$. We also found that our magnetite contained very dense hematite lamellae that run horizontally and vertically (see Figures 2A, 3A), and this suggests the occurrence of secondary high-temperature metamorphism. Furthermore, the presence of maghemite might indicate that our magnetite also experienced low-temperature oxidation such as induced by lightning strikes. Our XMCD spectra and the domain examination of our magnetite revealed the conversion of $\mathrm{Fe}^{2+}$ ions to $\mathrm{Fe}^{3+}$ ions and the presence of characteristic striped magnetic domains cut by biaxial hematite lamellae. As previously proposed by Salminen et al. (2009), these evidences of high-temperature oxidation suggest that Vredefort rocks have experienced hydrothermal alteration induced by an impact event, and hence the occurrence of impact-generated hydrothermal activity beneath the crater. It is posited that latter terrestrial lightning strikes on the hydrothermally oxidized magnetites intensified their magnetization.

\section{References}

Banfield, J. F., Wasilewski, P. J., and Veblen, D. R. (1994). TEM study of relationships between the microstructures and magnetic properties of strongly magnetized magnetite and maghemite. Am. Mineral. 79, 654-667.

Brice-Profeta, S., Arrio, M-.A., Tronc, E., Letard, I., dit Moulin, C. C., and Sainctavit, P. (2005). XMCD investigation of spin disorder in $\gamma-\mathrm{Fe}_{2} \mathrm{O}_{3}$

\section{Conclusion}

Using a SPELEEM, we observed striped magnetic domains subdivided by hematite lamellae in a high-coercivity coarsegrained magnetite obtained from Vredefort granite. In addition, $\mathrm{X}$-ray absorption spectra showed that the coarse-grained magnetite had been partially oxidized into maghemite, and XMCD analysis clarified the magnetic contribution of the octahedral $\mathrm{Fe}^{3+}$ ions. The array of hematite lamellae within the partially oxidized magnetite suggests that the rock has been affected by post-impact hydrothermal activity beneath the Vredefort crater. Latter terrestrial lightning strikes on the partially oxidized magnetite intensified its remanence.

\section{Acknowledgments}

I sincerely thank Prof. Roger Gibson and Mr. Cristo Mayer for their kind field guides around the Vredefort dome. The synchrotron radiation experiments were performed at the BL17SU of SPring-8 with the approval of the Japan Synchrotron Radiation Research Institute (JASRI) (Proposal No. 2011A1194 and 2012A1323). Mr. Mandai helped our SPLEEM measurements. This work was supported by JSPS KAKENHI Grant Number 22340146. 
Carporzen, L., Gilder, S. A., and Hart, R. J. (2005). Palemagnetism of the Vredefort meteorite crater and implications for craters on Mars. Nature 435, 198-201. doi: 10.1038/nature 03560

Carporzen, L., Weiss, B. P., Gilder, S. A., Pommier, A., and Hart, R. J. (2012). Lightning remagnetization of the Vredefort impact crater: no evidence for impact-generated magnetic fields. J. Geophys. Res. 117, E01007. doi: 10.1029/2011JE003919

Cloete, M., Hart, R. J., Schmidt, H. K., Mdrury, M., Demanet, C. M., and Vijaya, S. K. (1999). Characterization of magnetic particles in shocked quartz by means of electron- and magnetic force microscopy: Vredefort, South Africa. Contrib. Mineral. Petrol. 137, 232-245. doi: 10.1007/s004100050548

Colombo, U., Gazzarini, F., Lanzavecchia, G., and Sironi, G. (1965). Magnetite oxidation: a proposed mechanism. Science 147:1033. doi: 10.1126/science.147.3661.1033

Davis, P. M., and Evans, M. E. (1976). Interacting single-domain properties of magnetite intergrowths. J. Geophys. Res. 81, 989-994. doi: 10.1029/JB081i005p00989

Gallagher, K., Feitknecht, W., and Mannweiler, U. (1968). Mechanism of oxidation of magnetite to gamma- $\mathrm{Fe}_{2} \mathrm{O}_{3}$. Nature 217, 1118-1121. doi: 10.1038/2171118a0

Gibson, R., and Reimold, W. U. (2008). Geology of the Vredefort Impact Structure: A Guide to Sites of Interest. Pretoria: Council for Geoscience.

Goering, E., Gold, S., Lafkioti, M., and Schutz, G. (2006). Vanishing Fe 3d orbital moments in single-crystalline magnetite. Europhys. Lett. 73, 97. doi: 10.1209/epl/i2005-10359-8

Graham, K. W. T. (1961). The re-magnetization of a surface outcrop by lightning currents. Geophys. J. R. Astron. Soc. 6, 85-102. doi: 10.1111/j.1365246X.1961.tb02963.x

Harrison, R., Dunin-Borkowski, R. E., and Putnis, A. (2002). Direct imaging of nanoscale magnetic interactions in minerals. Proc. Natl. Acad. Sci. U.S.A. 99, 16556-16561. doi: 10.1073/pnas.262514499

Hart, R. J., Hargraves, R. B., Andreoli, M. A. G., Tredoux, M., and Doucourè, C. M. (1995). Magnetic anomaly near the center of the Vredefort structure: implications for impact-related magnetic signatures. Geology 23, 277-280.

Ivanov, B. A. (2005). Numerical modeling of the largest terrestrial meteorite craters. Solar Syst. Res. 39, 381-409 doi: 10.1007/s11208-005-0051-0

Kasama, T., Dunin-Borkowski, R. E., and Eerenstein, W. (2006). Off-axis electron holography observation of magnetic microstructure in a magnetite (001) thin film containing antiphase domains. Phys. Rev. B 73:104432. doi: 10.1103/PhysRevB.73.104432

Kotsugi, M., Mitsumata, C., Maruyama, H., Wakita, T., Taniuchi, T., Ono, K., et al. (2010). Novel magnetic domain structure in iron meteorite induced by the presence of $\mathrm{L1}_{0}$-FeNi. Appl. Phys. Exp. 3:013001. doi: 10.1143/APEX.3. 013001

Kotsugi, M., Mizuguchi, M., Sekiya, S., Ohkouchi, T., Kojima, T., Takanashi, $\mathrm{K}$, et al. (2011). Determination of local magnetic moment in $\mathrm{L}_{0}-\mathrm{FeNi}$ using photoelectron emission microscopy (PEEM). J. Phys. 266:012095. doi: 10.1088/1742-6596/266/1/012095

Kuiper, P., Searle, B. G., Rudolf, P., Tjeng, L. H., and Chen, C. T. (1993). X-ray magnetic dichroism of antiferromagnet $\mathrm{Fe}_{2} \mathrm{O}_{3}$ : the orientation of magnetic moments observed by Fe 2p X-ray absorption spectroscopy. Phys. Rev. Lett. 70, 1549-1552. doi: 10.1103/PhysRevLett.70.1549

Kuzmin, A., and Chaboy, J. (2014). EXAFS and XANES analysis of oxides at the nanoscale. Inter. Union Crystallogr. J. 1, 571-589. doi: $10.1107 / \mathrm{S} 2052252514021101$

McCarty, K. F., Monti, M., Nie, S., Siegel, D. A., Starodub, E., El Gabaly, F., et al. (2014). Oxidation of magnetite (100) to hematite observed by in situ spectroscopy and microscopy. J. Phys. Chem. (C) 118, 19768-19777. doi: $10.1021 /$ jp5037603

Monti, M., Santos, B., Mascaraque, A., de la Fuente, O. R., Niño, M. A., Menteş, T. O., et al. (2012). Magnetism in nanometer-thick magnetite. Phys. Rev. B 85, 020404(R). doi: 10.1103/physrevb.85.020404

Muundjua, M., Hart, R. J., Gilder, S. A., Carporzen, L., and Galdeano, A. (2007). Magnetic imaging of the Vredefort impact crater, South Africa. Earth Planet. Sci. Lett. 261, 456-468. doi: 10.1016/j.epsl.2007.07.044

Nakamura, N., Okuno, K., Uehara, M., Ozawa, T., and Fuller, M. (2010). "Coarsegrained magnetites in biotite as a possible stable remanence-carrying phase in
Vredefort granites," in Large Meteorite Impacts and Planetary Evolution IV, The Geological Society of America Special Paper, Vol. 465, eds R. L. Gibson and W. U. Reimold (Boulder, CO: The Geological Society of America, Inc.), 165-172.

Okudera, H., Yoshiasa, A., Murai, K., Okube, M., Takeda, T., and Kikkawa, S. (2012). Local structure of magnetite and maghemite and chemical shift in Fe K-edge XANES. J. Mineral. Petrol. Sci. 107, 127-132. doi: 10.2465/jmps. 110624

Osinski, G. R., Tornabene, L. L., Banerjee, N. R., Cockell, C. S., Flemming, R., Izawa, M. R. M., et al. (2013). Impact-generated hydrothermal systems on Earth and Mars. Icarus 224 347-363. doi: 10.1016/j.icarus.2012.08.030

Pearce, C. I., Michael, C., Henderson, B., Pattrick, R. A. D., van der Laan, G., and Vaughan, D. J. (2006). Direct determination of cation site occupancies in natural ferrite spinels by $\mathrm{L}_{2,3} \mathrm{X}$-ray absorption spectroscopy and X-ray magnetic circular dichroism. Am. Mineral. 91, 880-893. doi: 10.2138/am.2006.2048

Piquer, C., Laguna-Marco, M. A., Roca, A. G., Boada, R., Guglieri, C., and Chaboy, J. (2014). Fe K-edge X-ray absorption spectroscopy study of nanosized nominal magnetite. J. Phys. Chem. (C) 118, 1332-1346. doi: 10.1021/jp4104992

Quesnel, Y., Gattacceca, J., Osinski, G. R., and Rochette, P. (2013). Origin of the central magnetic anomaly at the Haughton impact structure, Canada. Earth Planet. Sci. Lett. 367, 116-122. doi: 10.1016/j.epsl.2013.02.032

Reimold, W. U., and Gibson, R. L. (1996). Geology and evolution of the Vredefort impact structure, South Africa. J. Afr. Earth Sci. 23, 125-162. doi: 10.1016/S0899-5362(96)00059-0

Salminen, J., Pesonen, L. J., Lahti, K., and Kannus, K. (2013). Lightninginduced remanent magnetization-the Vredefort impact structure, South Africa. Geophys. J. Int. 195, 117-129. doi: 10.1093/gji/ggt230

Salminen, J., Pesonen, L. J., Reimold, W. U., Donadini, F., and Gibson, R. L. (2009). Paleomagnetic and rock magnetic study of the Vredefort impact structure and the Johannesburg Dome, Kaapvaal Craton, South Africa - Implications for the apparent polar wander path of the Kaapvaal Craton during the Mesoproterozoic. Precambrian Res. 168, 167-184. doi: 10.1016/j.precamres.2008.09.005

Signorini, L., Pasquini, L., Boscherini, F., and Bonetti, E. (2006). Local magnetism in granular iron/iron oxide nanostructures by phase- and siteselective X-ray magnetic circular dichroism. Phys. Rev. B 74:014426. doi 10.1103/PhysRevB.74.014426

Tucker, P., and O'Reilly, W. (1980). Reversed thermoremanent magnetization in synthetic titanomagnetites as a consequence of high temperature oxidation. J. Geomagn. Geoelectr. 32, 341-355.

Verrier, V., and Rochette, P. (2002). Estimating peak currents at ground lightning impacts using remanent magnetization. Geophys. Res. Lett. 29, 1867. doi: 10.1029/2002GL015207

Waychunas, G. A., Apted, M. J., and Brown, G. E. Jr. (1983). X-ray K-edge absorption spectra of Fe minerals and model compounds: near edge structure. Phys. Chem. Min. 10, 1-9. doi: 10.1007/BF01204319

Wei, J. D., Knittle, I., Hartmann, U., Zhou, Y., Murphy, S., Shvets, I., et al. (2006). Influence of the antiphase domain distribution on the magnetic structure of magnetite thin films. Appl. Phys. Lett. 89, 122517. doi: 10.1063/1.2356308

Yokoyama, E., Nedelec, A., Baratoux, D., Trindade, R. I. F., Fabre, S., and Berger, G. (2015). Hydrothermal alteration in basalts from Vargeão impact structure, south Brazil, and implications for recognition of impact-induced hydrothermalism on Mars. Icarus 252, 347-365. doi: 10.1016/j.icarus.2015.02.001

Conflict of Interest Statement: The authors declare that the research was conducted in the absence of any commercial or financial relationships that could be construed as a potential conflict of interest.

Copyright $\odot 2015$ Kubo, Nakamura, Kotsugi, Ohkochi, Terada and Fukuda. This is an open-access article distributed under the terms of the Creative Commons Attribution License (CC BY). The use, distribution or reproduction in other forums is permitted, provided the original author(s) or licensor are credited and that the original publication in this journal is cited, in accordance with accepted academic practice. No use, distribution or reproduction is permitted which does not comply with these terms. 